\title{
JURIDICIDAD DE LAS ACTUACIONES DE LIQUIDADORES DENTRO DEL RÉGIMEN COOPERATIVO DE PANAMÁ
}

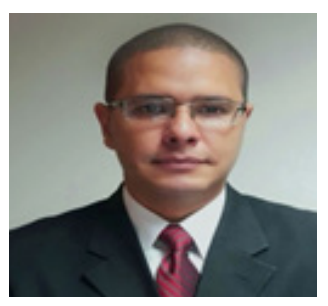

\section{Gino Osellame Rosillo}

Universidad Metropolitana de Educación, Ciencia y Tecnología, UMECIT, Panamá

ginoosellame@gmail.com

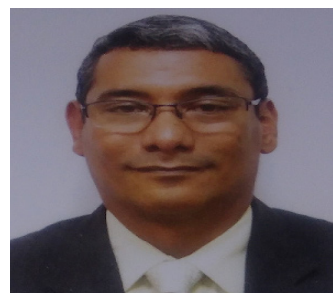

\section{Jaime Fong Buckridge}

Abogado

\section{RESUMEN}

Cuando una cooperativa está en liquidación, es necesario tener claro que se trata un proceso, cuyo objetivo se focaliza en ajustar las cuentas de dicha persona jurídica en estado de insolvencia, de tal manera que se determine lo que corresponda a los interesados, según sus derechos activos y pasivos. Por regla general, descansa en la figura jurídica del liquidador, el rol de llevar a cabo dicho proceso, y por tanto, es quien debe en resumidas cuentas inventariar, cobrar y pagar a quienes corresponda según su derecho. Si bien, las tres funciones básicas del liquidador (inventariar, cobrar y pagar), no resulta en la práctica, una actividad de somera ejecución. Se trata más bien, de ejercer funciones propias de cualquier administrador, con la diferencia que el liquidador, sólo tiene una masa de activos, para equilibrar pasivos, sin activar la operación original del fallido. En este sentido, el ejercicio de las funciones del liquidador está enmarcadas en instituciones jurídicas definidas como el mandato especial (Derecho Civil) y buenas prácticas de administración general, tal como lo expone de forma prístina el artículo 90 de la Ley 17 de 1 de mayo de 1997, a propósito de la representación legal de la comisión liquidadora, y su relación con la cooperativa.

Palabras clave: Liquidación, liquidadores, cooperativa, mandato, administración. 


\title{
JURIDICITY OF THE ACTIONS OF LIQUIDATORS WITHIN THE COOPERATIVE REGIME OF PANAMA
}

\begin{abstract}
When a cooperative is in liquidation, it is necessary to be clear that it is a process, whose objective is focused on adjusting the accounts of said legal entity in a state of insolvency, in such a way that it determines what corresponds to the interested parties, according to their rights actives and passives. As a general rule, it rests in the legal figure of the liquidator, the role of carrying out said process, and therefore, it is the person who must, in summary, inventories, collect and pay to whom it corresponds according to their right. Although, the three basic functions of the liquidator (inventory, collect and pay), does not result in practice, a shallow execution activity. It is rather, to exercise functions of any administrator, with the difference that the liquidator, only has a mass of assets, to balance liabilities, without activating the original operation of the bankrupt. In this sense, the exercise of the functions of the liquidator is framed in legal institutions defined as the special mandate (Civil Law) and good practices of general administration, as it is explained in a pristine way in Article 90 of Law 17 of May 1 of 1997, regarding the legal representation of the liquidation commission, and its relationship with the cooperative.
\end{abstract}

Keywords: Liquidation, liquidators, cooperative, mandate, administration, assets, liabilities, insolvency, rights, obligations, members, association.

\section{INTRODUCCIÓN}

\section{DEL DERECHO COOPERATIVO EN PANAMÁ Y EL PROCESO LIQUIDATORIO.}

En la República de Panamá las cooperativas, definidas como asociaciones de utilidad pública, de interés social y de derecho privado, se rigen por un marco regulatorio constituciones y un régimen especial, que le dan forma al denominado derecho cooperativo.

Las cooperativas son asociaciones que no tienen fines de lucro, su causa es la solidaridad. (TALEVA SALVTA, 2016). Este carácter especial, hace que el cooperativismo, como actividad social, pero no menos financiera, sea regulada, en el caso de Panamá, por una autoridad supervisora, como lo es el Instituto Panameño Autónomo Cooperativo (en adelante IPACOOP). 
Juridicidad de las actuaciones de liquidadores dentro del régimen cooperativo de Panamá Gino Osellame Rosillo y Jaime Fong Buckridge (60:78)

La Constitución Política establece en su artículo 286, en relación a las cooperativas lo siguiente:

El Estado creará por medio de entidades autónomas o semiautónomas o por otros medios adecuados, empresas de utilidad pública. En igual forma asumirá, cuando así fuere necesario al bienestar colectivo y mediante expropiación o indemnización, el domino de las empresas de utilidad pública pertenecientes a particulares, si en cada caso lo autoriza la Ley.

El desarrollo positivo del derecho cooperativo, lo encontramos en una caudal de normas, a saber, la llamada Ley de cooperativas y sus reglamentaciones:

1) Ley 17 de 1 de mayo de 1997, por la cual se desarrolla el Artículo 283 de la Constitución Política y se establece el Régimen Especial de las Cooperativas.

2) Decreto Ejecutivo 39 de 22 de octubre de 1998, por el cual se reglamenta la Ley 17 de 1 de mayo de 1997, sobre el régimen especial de las cooperativas.

3) Decreto Ejecutivo 137 de 5 de noviembre de 2001, por el cual, por el cual se reglamenta la Ley 17 de 1 de mayo de 1997, sobre el régimen especial de las cooperativas.

4) Decreto Ejecutivo 33 de 6 de mayo de 2002, por el cual se modifica y adiciona el Decreto Ejecutivo 137 de 5 de noviembre de 2001, que reglamenta la Ley 17 de 1 de mayo de 1997, sobre el Régimen Especial de las Cooperativas.

5) Resolución J.D./No.3/2007, mediante el cual se adopta el reglamento de procedimiento de las comisiones liquidadoras.

6) Resolución J.D./No.11-A/2010, por la cual se reforma el Artículo 23 del Reglamento de las Comisiones Liquidadoras del Instituto Autónomo Cooperativo;

Por su parte la Ley 17 de 1 de mayo de 1997, dispone en su artículo 92 una serie de deberes que son de forzoso acatamiento, en este caso por los liquidadores de la Comisión de Liquidadora de una cooperativa.

Sobre el tema de la responsabilidad, de los liquidadores, la redacción del legislador, fue mezquina al desarrollar las funciones generales en una cooperativa, por lo que debió incluirse, posteriormente, mediante reglamento obligaciones que son esenciales, para el ejercicio de las funciones de la comisión liquidadora y de sus integrantes.

De hecho, una de las obligaciones que describiremos, es precisamente piedra angular, para salvaguardar las potenciales obligaciones que deriven del proceso de liquidación, sobre la figura 
de los liquidares en ejercicio del cargo que ocupan.

En primer lugar, realizar los pagos, según el orden de prelación contenido en la Ley 17 de 1 de mayo de 1997. En segundo lugar, se establece la facultad a favor de la comisión liquidadora de ceder a otra cooperativa, de la misma localidad o a los acreedores de la cooperativa, los créditos que tengan por cobrar a sus asociados o terceros.

Con esto se reafirma que la cesión de créditos es una decisión procedente si así lo decide la comisión liquidadora, que depende de la conveniencia, oportunidad, y provecho que surta dentro del proyecto de liquidación, siendo el verbo "podrá", la puerta abierta que dará la capacidad de decisión a la comisión para tal fin. Seguidamente de forma adjetiva, se establece una obligación cabal e importante, es decir, el deber de que las acciones de la comisión liquidadora deben ser previamente coordinadas con el IPACOOP.

Esta última obligación, cierra el círculo de la representatividad o naturaleza de la figura de los liquidadores y de la responsabilidad derivada de sus acciones en dicho cargo, teniendo pues que las funciones del liquidador se equiparan a las de un mandatario ejerciendo la administración, en este caso de una masa de activos y pasivos no operativos, con un objetivo fundamental que corresponda a la mayor satisfacción económica de los acreedores.

En el año 2007, pasados 10 años desde la promulgación de la llamada Ley de cooperativas, el Instituto Panameño Autónomo de Cooperativas (IPACOOP), profiere la Resolución J.D. 3/2007, mediante el cual se adopta el reglamento de procedimiento de las comisiones liquidadoras: la cual dará forma y sustancia a las obligaciones de la Comisión Liquidadora.

\section{A. La Disolución y Liquidación de cooperativas:}

Por otro lado, debemos entender por liquidación, al conjunto de operaciones realizadas para determinar lo concerniente a cada uno de los interesados en los derechos activos y pasivos de un negocio, patrimonio u otra relación de bienes y valores. (CABANELLAS, 1972)

La liquidación de una cooperativa es la conclusión o cesación de sus actividades, en virtud de las trasgresiones al régimen legal o por el hecho de haber incurrido en irregularidades que trastocaron las condiciones con las que se le concedió la autorización para funcionar y, posteriormente, realizar sus activos para el pago de los pasivos. 
Puede también, ser de forma acuerdo voluntario, debido a la naturaleza de la acción, la cual, tiene su génesis en las dos terceras (2/3) partes de los asociados reunidos en asamblea, según las causales establecidas, en el artículo 87, de la Ley 17 de 1 de mayo de 1997.

La jurisprudencia y la doctrina lo denominan un acuerdo negativo, lo cual no es cosa distinta de la aplicación del principio de que en derecho las cosas se deshacen como se hacen (CAICEDO VASCO, 2017).

Una vez establecida la disolución, se adelanta la liquidación, que consiste en determinar el estado real de la entidad, contable, financiera, tributaria y laboralmente, con la finalidad de determinar sus activos y pasivos, para proceder a efectuar los pagos que sean necesarios y terminar con la destinación de los remanentes o sobrantes, si los hay, a otra entidad de naturaleza semejante o a una entidad de beneficencia. Este procedimiento lo adelanta el liquidador o, en su defecto, el representante legal, quien actúa como liquidador. (GAITÁN SANCHEZ, 2014)

Cualquier entidad cooperativa puede decidir su disolución y su liquidación por la mera voluntad de las terceras (2/3) partes de los asociados reunidos en asamblea, por cualquiera de las siguientes causas:

1. Disminución del número de asociados a menos del mínimo fijado por esta Ley o por su reglamento.

2. Imposibilidad de realizar el objetivo específico para el que fue constituida, o por extinción de éste.

\section{Estado de insolvencia.}

4. Fusión o incorporación a otra asociación cooperativa. Las cooperativas fusionadas o incorporadas dejarán de existir en la fecha en que la fusión o incorporación quede inscrita en el Registro de Cooperativas.

5. Por cualquier causa que haga imposible el cumplimiento de sus fines sociales o económicos.

Una vez que se encuentre con al menos una de las causas la misma será idónea para que sea usada por una asamblea de dos terceras partes de asociados, o en su defecto por el IPACOOP de oficio.

Para ello, el IPACOOP, constituirá una comisión liquidadora integrada por tres personas; una nombrada por la federación respectiva u otro organismo de integración, y dos nombradas por el mencionado instituto. 


\section{B. La representación legal de cooperativa, en estado de liquidación:}

La comisión liquidadora ejercerá la representación legal de la cooperativa, y le corresponde realizar el activo y cancelar el pasivo. La actual representación la establece el imperio de la Ley 17 de 1 de mayo de 1997, y dicha representación es legalmente abarcadora a todos los asuntos administrativos necesarios para realizar el activo y cancelar el pasivo de la cooperativa.

Es de suma importancia recordar en lo relativo a la representación legal que se le otorga a la comisión liquidadora que la misma ejercerá dicha representación de la forma que lo disponga la Ley o regulación específica aplicable; de no existir regulación o legislación para acciones que deba ejecutar la comisión liquidadora, las mismas se realizarán dentro del marco que según la naturaleza del negocio, haría un buen padre de familia (más adelante ahondaremos en este tema).

\section{Acuerdo de disolución.}

El acuerdo de disolución será comunicado al IPACOOP, en un término no mayor de ocho días siguientes a su aprobación. Decretada la disolución, la Cooperativa quedará en estado de liquidación

c. Deberes de la Comisión Liquidadora.

c.1. Poner en conocimiento del público el acuerdo de disolución, mediante aviso, por cinco publicaciones, en periódicos de circulación nacional.

La ley obliga a personas, empresas e instituciones públicas y privadas a publicar ciertos avisos, actas u otros documentos que en la doctrina legal son conocidos como actos o negocios jurídicos cuya finalidad de acción es la de que exista el mayor conocimiento general posible por parte del mercado social lo que ocasiona un ambiente de transparencia que revista al mencionado acto.

\section{c.2. Concluir las operaciones pendientes al momento de la disolución.}

La comisión liquidadora debe concluir las operaciones sociales pendientes al momento de la disolución. De lo anterior se desprende que la comisión liquidadora sólo se encuentra facultada para realizar actos encaminados a la efectiva liquidación de la Cooperativa, así como para terminar aquellas operaciones sociales pendientes de ejecución al tiempo de la apertura del trámite de la disolución o liquidación. Ello significa que la mencionada comisión liquidadora (administrador) durante la liquidación no puede celebrar ni ejecutar nuevos actos o contratos que impliquen el desarrollo del objeto social, en razón a que la Cooperativa carece de capacidad jurídica para tal fin 
Juridicidad de las actuaciones de liquidadores dentro del régimen cooperativo de Panamá Gino Osellame Rosillo y Jaime Fong Buckridge (60:78)

además de la responsabilidad solidaria e ilimitada que le cabría al liquidador por la realización de nuevas actividades sociales

c.3. Efectuar el inventario de los activos patrimoniales, de los pasivos de cualquier naturaleza, de los libros y de los documentos.

Este acto conlleva la distribución, identificación y ubicación de todos los bienes, (activos fijos de mobiliarios y enseres al igual que los equipos tecnológicos tangibles e intangibles) adquiridos por la Cooperativa, mediante compra, donación, permuta, transferencia, o por cualquier otra modalidad.

c.4. Exigir cuenta de su administración a las personas que hayan manejado intereses de la Cooperativa y no hayan obtenido el finiquito correspondiente, así como poner en conocimiento de las autoridades judiciales las denuncias correspondientes.

La comisión liquidadora es el ente a quien le compete la guarda de la integridad de los activos y pasivos de la Cooperativa y para ello el presente deber que le recae pertinente a la revisión de administraciones previas o anteriores que por algún motivo no hayan presentado el finiquito correspondiente. En consecuencia, la mencionada comisión liquidadora tiene no solo tiene el deber sino que por imperio del artículo 90, de la Ley 17 de 1 de mayo de 1997 también le recae el Derecho de Denunciar y/o querellar ante las autoridades correspondientes (ante el 11 Ministerio Publico de la República de Panamá, ejemplo Fiscalía, Procuraduría, Centro de Recepción de Renuncias del Ministerio Público).

c.5. Liquidar y cancelar las cuentas de la cooperativa a cada uno de los asociados y terceros, conforme el orden de prioridad.

Esto según el orden de prioridad, que se encuentra descrito en el artículo 93 de la Ley 17 de 1 de mayo de 1997, a saber: Gasto de liquidación, salarios y prestaciones sociales causadas hasta el momento de la disolución, el de los certificados de inversión y otros títulos-valores, cancelación de las obligaciones contraídas con sus acreedores, devolución, a los asociados, del valor de sus aportaciones o la parte proporcional que les corresponda, en caso de que el haber social no fuera suficiente, distribuir entre los asociados sus aportaciones y los excedentes pendientes de pago, entregar el saldo final, si lo hubiere, al IPACOOP.

c.6. Cobrar los créditos, percibir su importe y otorgar los correspondientes finiquitos.

El término finiquito se utiliza para designar a un documento que se aplica en los casos en los que una relación debe finalizarse por diversas razones. El finiquito es un documento muy importante ya que es el que pone en perspectiva el trabajo realizado por una de las partes y contiene la información necesaria para cuando el vínculo laboral sea finalizado. 


\section{c.7. Enajenar los Bienes de la Cooperativa.}

En un sentido jurídico, la enajenación implica la transferencia de un derecho real de un patrimonio a otro. La voz enajenación puede ser usada en un modo amplio o en un modo estricto. En un sentido amplio, enajenación implica la transferencia del dominio o cualquier otro derecho real entre dos patrimonios. Mientras que, en un sentido estricto, la enajenación se refiere sólo al derecho real de dominio y no a los demás.

La enajenación es la consecuencia jurídica de una obligación de dar, que es precisamente aquella que busca transferir el dominio o constituir un derecho real en su favor.

Con todo, la enajenación puede afectar a la cosa entera o a una parte de la misma (esto dependerá de la estrictamente de la libre voluntad del enajenador por un lado y a la naturaleza de la cosa por el otro) si es materialmente divisible (se refiere a la cosa) sin desaparición de su utilidad (sine damno) y siempre y cuando el disponente (o enajenador) sea titular único del derecho de propiedad.

c.8. Informar periódicamente del estado de la liquidación a los asociados y acreedores.

$\mathrm{El}$ acto de informar es un proceso unidireccional, que consiste en dar a conocer estado de la liquidación a los asociados y acreedores, ahora bien este acto en el presente caso debe ser ejecutado regularmente

c.9. Rendir cuentas periódicas de su mandato y, al final de la liquidación, presentar el informe respectivo y obtener del IPACOOP el finiquito.

El citado mandato se realiza entre dos o más partes, en él una de las partes confía la gestión de uno o más negocios, el cual es denominado mandante (IPACOOP), a otra que se hace cargo de ellos por cuenta y riesgo del mandante, dicho encargado se denomina como mandatario (Cooperativa).

El presente mandato que concibe obligaciones contractuales equivalentes y recíprocas entre las partes, reviste la característica de ser oneroso; cuyos honorarios serán fijados y regulados por el IPACOOP, esta remuneración es definida en el mismo acto de constitución de la comisión, por la ley por lo que dispone el art. 89 de la Ley 17 de 1 de mayo de 1997. Encontrándose el propio la naturaleza de la figura del mandato dentro de nuestro código Civil en libro cuarto de las obligaciones en general y de los contratos en el título VIII "Del Mandato". 
c.10. Los demás que se deriven de la naturaleza de la liquidación y del propio mandato.

El presente enunciado de deber de la comisión liquidadora, presenta la condición en numerus apertus de probabilidades que dimanen de la naturaleza propia del mandato y la liquidación, lo que abarca todos los deberes que deba ejecutar la comisión liquidadora en una administración tal como lo haría un buen padre de familia; en consecuencia, las situaciones específicas lejos de ser limitadas no lo son, sino que a contrario sensu son ilimitadas.

\section{Orden de Prelación en ocasión de Liquidación}

\section{El mandato inmerso en el proceso liquidatario:}

De las normas anteriores, en la que se apremia la necesidad de designar liquidadores, bajo la figura de un triunvirato o mejor llamada comisión liquidadora, se configura jurídicamente una relación de mandato. Resulta obvio que no será un mandato contractual, pero si un contrato cuya fuente es precisamente la Ley, que busca mutar un estado de cosas, para darle una consistencia que corresponda a una situación extraordinaria, tal como lo es el cese de operaciones de una cooperativa, forzada precisamente por quien regenta públicamente sus funciones.

Tenemos entonces que el mandato, según nuestras reglas positivas en materia civil (artículo 1400 del Código Civil), es cuando una persona se obliga a prestar algún servicio o hacer alguna cosa, por cuenta o encargo de otra.

Para el caso del régimen cooperativo, se encuentra regulado en la Ley 17 de 1 de mayo de 1997, artículo 90, el cual establece que la comisión liquidadora ejercerá la representación legal de la cooperativa, y le corresponde realizar el activo y cancelar el pasivo.

En base a lo anterior, es el liquidador un verdadero mandatario y representante legal de la cooperativa y como tal, le compete hacer presente al ente jurídico en sus relaciones judiciales y extrajudiciales. El mandato establecido por Ley, tal como se le aplica al régimen cooperativo, es denominado mandato especial.

Así mismo lo encontramos en el mandato establecido en el Código de Comercio, en relación a la liquidación de personas jurídicas mercantiles, la Ley 32/1927, exclusivamente para sociedades anónimas, la Ley 4 de 2009, de sociedades de responsabilidad limitada, la Ley de bancos (Decreto Ejecutivo 52 de 2008), y el régimen de seguros (Ley 12 de 2012), por citar algunas. Entonces, el 
mandato que se confiere a favor de los liquidadores, es simplemente el de ejecutar el proceso de liquidación.

Este mandato especial, es decir, desarrollado no por acuerdo de las partes, tal como inicia en el derecho ordinario, tiene su génesis en la Ley que se activa frente a situaciones críticas muy identificadas. Por tanto, cabe preguntarse quién es la contraparte, o vale preguntar quién es realmente su mandante.

Por un lado tenemos que las cooperativas cumplen una función pública, común y afín a un conglomerado de personas, por tanto, el Estado al fomentar el desarrollo de este tipo de personas jurídicas, tiene un interés legítimo para supervisar las todo en cuanto a esta, de hecho esta es la justificación de crear una institución como lo es el Instituto Panameño Autónomo de Cooperativas (IPACOOP).

No obstante, lo anterior, la mismo norma nos aclara que la comisión liquidadora será representante de la cooperativa en proceso de liquidación, lo que se deduce que el mandante dentro de esta situación lo será la misma cooperativa y no el Estado como responsable constitucional de este tipo de operaciones económicas, tal cual, lo establece la Constitución Política.

Ahora bien, pese a que el citado artículo 90 dispone que la comisión liquidadora sea la representante legal, debemos apuntar que el mandato se diferencia de la representación en que ésta es el género, y aquél la especie.

Luego de lo anterior, nuestro régimen cooperativo establece funciones claras para la comisión de liquidadores de cooperativas en proceso de liquidación, las cuales se convierten en funciones y deberes inobservables por parte de esta corporación, contenidas en el reglamento para el procedimiento de liquidaciones de cooperativas (Resolución J.D. 3/2007).

Entre los deberes se describen taxativamente:

1. Presentar el Proyecto de Liquidación a la Dirección Provincial del IPACOOP;

2. Solicitar al IPACOOP el informe que sustentó la disolución de la cooperativa, para su revisión y guía en el proyecto de liquidación;

3. Poner en conocimiento del público la resolución de disolución de la cooperativa;

4. Liquidar y cancelar las cuentas de la cooperativa a cada uno de los asociados y terceros conforme al orden de prioridad, establecido en la Ley 17 del $1^{\circ}$ de mayo de 1997;

5. Cobrar los créditos, percibir su importe y otorgar los correspondientes finiquitos; 
Juridicidad de las actuaciones de liquidadores dentro del régimen cooperativo de Panamá Gino Osellame Rosillo y Jaime Fong Buckridge (60:78)

6. Informar periódicamente del estado de la liquidación a los asociados y acreedores;

7. Levantar un acta de cada una de las reuniones que realice, las cuales deben establecer los temas tratados y será firmada por los comisionados presentes en la reunión;

8. Ejecutar las actividades aprobadas en el proyecto de liquidación;

9. Presentar un informe mensual a la Dirección Provincial de los avances de la liquidación;

10. Llevar un registro diario de entradas y salidas de efectivo por orden de fecha, de todas las operaciones relativas a la liquidación;

11. Los demás que se deriven de la naturaleza de la liquidación y del propio mandato;

12. Presentar un informe final que incluya los fondos recibidos en efectivo, total del patrimonio a liquidar, el detalle de los ingresos y egresos y el saldo final, con los originales de todos los comprobantes de entradas y salidas de dinero.

Por su parte, también dentro del procedimiento de liquidación, se establecen como funciones de la comisión liquidadora, las que siguen a continuación:

1. Informar a los bancos e entidades crediticias, con las que las cooperativas tengan vínculo, el nombramiento de la Comisión Liquidadora, a fin de realizar los cambios en el manejo de las cuentas;

2.Efectuarelinventariodelosactivosypasivos, deloslibrosydemásdocumentosdelacooperativa;

3. Concluir las operaciones pendientes al momento de la disolución;

4. Exigir cuenta de su administración a las personas que hayan manejado intereses de la cooperativa; y no hayan obtenido el finiquito correspondiente;

5. Denunciar antes las autoridades judiciales las acciones u omisiones que a su juicio constituyan delitos, realizados en perjuicio de la cooperativa por asociados, directivos u otras personas;

6. Enajenar los bienes de la cooperativa;

7. Los demás que se deriven de la naturaleza de la liquidación y del propio mandato.

Pareciera entonces, que los límites del mandato están expuestos en estos contenidos positivos, sin embargo, dentro de estos deberes y funciones, mal se podría pensar que los liquidadores serían una masa de inertes personeros que buscan sólo realizar una operación aritmética de suma y resta entre el debe y el haber, o entre activos y pasivos.

El liquidador tiene una función primigenia que es administrar una masa de bienes y derechos, con el objetivo de ponerlo acorde a los reclamos validados en manos de los acreedores y personas perjudicadas directamente por la fallida operación, para este caso de una cooperativa. 
El fundamento legal del argumento arriba expuesto, lo encontramos en el artículo sétimo de la Resolución J.D. 3/2007, literal g (sobre las funciones de la comisión liquidadora), que establece de plano:

g) Los demás que se deriven de la naturaleza de la liquidación y del propio mandato.

Por lo anterior, este numerus apertus de funciones, es la génesis para que el liquidador no sólo adopte tal papel, sino que se convierta en un administrador formal, dentro del proceso de liquidación (tema que profundizaremos más adelante), para poder alcanzar los fines propios de este procedimiento especial.

\section{E. El Liquidador como Administrador de la Liquidación:}

Mencionamos con anterioridad, que la función del liquidador se equipara con la de administrador, solamente en cuanto al proceso de liquidación y los bienes materiales o inmateriales, que le toca recaudar, para satisfacer las obligaciones dejadas por el fallido.

Por tanto, no se trata de un administrador común y corriente, sino de un administrador de bienes que reunidos, tienen cono fin ser liquidados, para honrar acreencias, por lo que la responsabilidad de los liquidadores se equipara a la de los administradores, dado que administran la sociedad cuando entra en fase de liquidación. La figura del administrador comprende una serie de derechos y obligaciones para con la liquidación que se administra. Como administrador el representante de la cooperativa, por lo que actuará en su nombre para realizar todo tipo acciones que la misma requiera, por tanto, será el responsable de la gestión del mandato especial a él concedido y responderá por lo actos realizados, que extralimiten el mandato y las reglas básicas de administración.

El mandato especial que recibe el liquidador, otorga facultades de hacer actos muy básicos de administración tales como:

1. Pagar las deudas y cobrar los créditos.

2. Perseguir en juicio a los deudores.

3. Intentar las acciones posesorias e interrumpir las prescripciones.

4. Contratar las reparaciones de las cosas que administra.

5. Comprar los materiales necesarios para el cultivo o beneficio de los objetos que se le hayan encomendado.

Se entiende plenamente cumplido el mandato, no solo por la ejecución de la liquidación encomendada, sino también por los medios utilizados a través de los cuales el liquidador, estableció 
que debía ejecutarse la administración de la masa de bienes (activos y pasivos), sujetos al proceso de liquidación. A propósito de este tema, nuestro Código Civil expresa en materia de responsabilidad para administradores, representantes, apoderados y liquidadores, que cuando una obligación no exprese algún cumplimiento, deber o funciones especiales, se exigirá para éstos que cumplan con la diligencia de un buen padre de familia.

El artículo 989 del Código Civil, sobre este tema advierte:

Artículo 989. La culpa o negligencia del deudor consiste en la omisión de aquella diligencia que exija la naturaleza de la obligación y corresponda a las circunstancias de las personas, del tiempo y del lugar.

Cuando la obligación no exprese la diligencia que ha de prestarse en su cumplimiento, se exigirá la que correspondería a un buen padre de familia (lo subrayado es nuestro).

En su carácter de administrador por mandato especial, la institución del liquidador, queda sujeta a la responsabilidad que deriva, del uso inadecuado de las debidas diligencias, para el ejercicio de la administración, por lo que responderá por dolo y por culpa, ante la diatriba de no hacer la diligencia de un buen padre de familia, salvando claro está los estándares de éste con la figura de una persona, a quien se le exige perfiles guardados, para ser designado liquidador.

Los límites para el ejercicio de la debida administración, del proceso de liquidación por parte de los liquidadores, y ante las funciones tan elementales que la Ley y las reglamentaciones impone a la comisión liquidadora, podría llevar evidentes confusiones o dudas, a ésta acerca de qué hacer frente a situaciones que no están contempladas en el catálogo de deberes y funciones de la comisión liquidadora.

La respuesta es solo una, es decir, diligenciar bajo los principios básicos de administración y las reglas generales del derecho. Así lo permite evidenciar la doctrina, según el criterio del jurista argentino Carlos A. Ghersi (1999), en su trabajo TEORIA GENERAL DE LA REPARACION DE DAÑOS:

"Todo derecho observa en su ejercicio límites específicos que se hayan enraizados en su propia naturaleza. A su vez, la actuación de todo sujeto deberá adecuarse al marco impuesto por los principios generales del derecho", lo cual supone la adecuación de dicho ejercicio a la finalidad económica o social para la cual el derecho subjetivo ha sido creado, sostiene el autor arriba mencionado" (GHERSI, 1999). 
Por su parte la Corte Suprema de Justicia, sobre el límite del abuso en el ejercicio de un derecho, nos aclara:

"No siempre resulta sencillo establecer con claridad si estamos frente a una conducta culposa en relación con un obrar o hecho determinado. A tales fines es necesario tomar en consideración ciertas pautas o criterios, tales como aquellos que hacen referencia a la que hubiese sido la conducta con que se habría comportado, en las mismas condiciones y circunstancias, un buen padre de familia, un buen hombre de negocios o un buen profesional"

...y sigue diciendo:

"Cabe la posibilidad de que se produzca un acto abusivo en el ejercicio de un derecho, cuando ha habido manifiesta intención de perjudicar a otro, a un tercero, aún sin que dicha actuación haya originado un beneficio propio. Asimismo, se producirá el ejercicio abusivo del derecho si está claro que la actuación materializada es contraria a la función económico-social inherente al derecho que se ejerce. En cualquier caso, habrá que tener en cuenta la situación particular de que se trate, pero siempre ha de tenerse presente, como criterio importante para establecer la existencia del acto abusivo, que la desviación en el ejercicio del derecho conduzca a apartarlo de la función social que lo justifica"

(Sentencia: Bank of Credit and Commerce International (Overseas) Ltda. (en liquidación) recurre en casación en el proceso ordinario que le sigue Omar Elías Solano Aparicio. Magistrado ponente: Eligio A. Salas. Panamá, once (11) de febrero de dos mil (2000).

\section{F. Deberes de los Liquidadores en el Sistema Financiero Nacional}

Debemos tener claros que la liquidación de una cooperativa, no opera bajo la égida del Derecho Comercial, ya que el fin social, para el cual son creadas este tipo de persona jurídica, lo separa del régimen de las sociedades mercantiles, y del régimen especial que la norma subjetivamente, desarrolla para actos de comercio determinados.

Tampoco para la liquidación de las cooperativas, debemos hacer uso abusivo de las normas civiles, ya que la competencia para este caso viene dada por una norma especial, sus reglamentos y resoluciones emitidas por su ente regulador. 
Juridicidad de las actuaciones de liquidadores dentro del régimen cooperativo de Panamá Gino Osellame Rosillo y Jaime Fong Buckridge (60:78)

No obstante, lo anterior, es prudente que, por analogía, se tomen en cuenta alguna de las funciones, que dentro de otros regímenes especiales, se tiene para el procedimiento de liquidación, y las funciones de los liquidadores:

1. Régimen jurídico de aseguradoras y reaseguradoras: Según la Ley 12 de 3 de abril de 2012. Que regula la actividad de seguros; dentro de los deberes de los liquidadores encontramos, en relación directa al procedimiento de liquidación los siguientes:

a. Imprimir celeridad al proceso de liquidación a fin de hacer líquidos con la mayor prontitud posible, las acreencias que hubiere.

b. Realizar su gestión con transparencia y simplicidad.

c. Respetar los derechos y prelaciones dispuestas por la Ley de seguros.

2. Régimen jurídico del sistema bancario: El Decreto Ejecutivo 52 de 30 de abril de 2008, que adopta el Texto Único de la Ley Bancaria, establece claramente cuáles son las facultades de los liquidadores dentro del régimen bancario nacional, a saber:

a. Suspender o limitar el pago de las obligaciones del banco y de las deudas de la masa según la disponibilidad de los recursos.

b. Emplear al personal necesario y separar del cargo a aquellos empleados cuya actuación dolosa o negligente haya propiciado la liquidación, así como a aquellos empleados que, por reducción de las actividades del banco, sean innecesarios.

c. Atender la correspondencia y otorgar cualquier documento a nombre del banco.

d. Administrar, controlar y custodiar los activos del banco.

e. Ceder o vender activos de acuerdo con su valor realizable, neto de provisiones, reservas y cualquier otro ajuste que determine la Superintendencia, conforme a las normas y regulaciones prudenciales existentes.

f. Transferir total o parcialmente los activos y pasivos del banco a una entidad con licencia para ejercer el negocio de fideicomiso en Panamá, previa autorización de la Superintendencia. g. Ejecutar los actos y celebrar los contratos que sean del giro de sus atribuciones que permitan el inicio, perfeccionamiento y ejecución de la liquidación a través del traspaso de activos y pasivos y del fideicomiso.

h. Establecer en el contrato de fideicomiso los mandatos, términos y condiciones para la conducente liquidación de activos y pasivos transferidos.

i. Cualquier otra facultad que, previa solicitud fundada del liquidador o de la junta de liquidación, sea autorizada por el Superintendente para un propósito determinado.

3. Régimen de valores: Según lo dispuesto en el Decreto-Ley 1 de 1999; por el cual se crea La Comisión Nacional de Valores y se regula el Mercado de Valores en la República de Panamá, sus leyes reformatorias y el Título II de la Ley 67 de 2011, el liquidador gestionará la enajenación y la realización de todos los bienes, los activos financieros, los derechos y los demás activos de la 
institución registrada en las condiciones más ventajosas posibles, de conformidad con las siguientes reglas:

a. Tratándose de muebles o inmuebles, derechos u otros bienes cuyo valor sea menor de veinte mil balboas (B/.20,000.00), el liquidador podrá venderlos por un valor que no podrá ser inferior a aquel que resulte de un avalúo practicado por uno o dos peritos idóneos independientes. El liquidador determinará, según las circunstancias, si el avalúo a que se refiere este numeral habrá de ser efectuado por uno o dos peritos. En aquellos casos de valores que se negocian en un mercado de valores no será necesario cumplir con el avalúo antes mencionado.

b. Tratándose de bienes muebles o inmuebles, derechos u otros bienes cuyo valor exceda de veinte mil balboas (B/.20,000.00), el liquidador podrá venderlos mediante subasta privada, siguiendo al efecto el procedimiento de remate o venta judicial contemplado en los artículos 1708 y siguientes del Código Judicial, en la medida en que sean aplicables. En aquellos casos de valores que se negocian en un mercado de valores no será necesario observar el procedimiento de subasta y podrán ser vendidos a través del mercado de valores.

c. Tratándose de créditos hipotecarios, prendarios o de cualquiera otra naturaleza, se confiere a la Superintendencia jurisdicción coactiva para la ejecución de dichos créditos aplicando para ello las normas sobre procesos ejecutivos contenidas en el Código Judicial. La Superintendencia podrá delegar sus atribuciones en uno de sus funcionarios para que actúe como juez ejecutor siempre que sea abogado idóneo. Y termina exponiendo esta norma, que lo anteriormente descrito, es sin perjuicio de la facultad del liquidador de ceder los créditos a otras instituciones registradas o bancarias.

\section{CONCLUSIONES:}

Luego del análisis realizado, la revisión y estudio de la normativa vigente y la doctrina; podemos advertir que, en términos generales, las potestades y obligaciones de los Liquidadores de una Cooperativa, son todas aquellas que posee un administrador actuando mediante mandato, limitado por el hecho de que el negocio llamados a administrar lo harán con la irónica tarea de no generar lucro, sino todo lo contrario, sacarla del mercado. Pero dentro de este proceso de liquidación y según la dimensión de la cooperativa, es evidente que se enfrentaran a situaciones que exigirán el actuar de un administrador; situaciones que pasaran desde las de tipo laboral como comercial, obviamente las administrativas y aquellas por las que taxativamente fueron nombrados, y en ese sentido el Comité Liquidador debe tener presente que para evitar cuestionamientos a su gestión debe, además de cumplir con las normas positivas que regulan sus acciones, procurar siempre poder justificar su actuar dentro de lo que se conoce en Derecho como "la diligencia de un buen padre de familia". 
En la medida que las actuaciones del Comité Liquidador se demuestren que fueron realizadas por el interés superior de la tarea encomendada y que la administración se manejó con la diligencia de un buen padre de familia, sus actos serán plenamente justificables.

Es importante tener presente que su responsabilidad no se limita a sus acciones exclusivas sino a aquellas que ejecuten sus subordinados, tal como lo establece la Corte en Fallo de 26 de diciembre de 2007

“... La responsabilidad que le corresponde a determinadas personas por las acciones u omisiones culposas realizadas por otras personas sobre las cuales tienen el deber de responder, tales como los padres con respecto a los hijos o los dueños de un establecimiento o empresa respecto de los perjuicios causados por sus dependientes, durante la prestación de sus funciones dentro de dicho establecimiento o empresa. En estos casos, la citada disposición legal establece que la carga de la prueba la tiene la persona que debe responder por la que realizó el acto u omisión culposo, quien deberá para poder eximirse de dicha responsabilidad, demostrar que empleó "toda la diligencia de un buen padre de familia para prevenir el daño" ocasionado por su dependiente.

Artículo 1645. La obligación que impone el Artículo 1644 es exigible no sólo por los actos u omisiones propios, sino por los de aquellas personas de quienes se debe responder.

El padre y la madre son responsables solidariamente de los perjuicios causados por los hijos menores o incapacitados que están bajo su autoridad y habitan en su compañía.

Los son igualmente los dueños o directores de un establecimiento o empresa respecto de los perjuicios causados por sus dependientes en el servicio de los ramos en que los tuvieran empleados, o con ocasión de sus funciones.

El Estado, las instituciones descentralizadas del Estado y el Municipio son responsables cuando el daño es causado por conducto del funcionario a quien propiamente corresponda la gestión practicada, dentro del ejercicio de sus funciones. Son, por último, responsables los maestros o directores de artes y oficios respecto a los perjuicios causados por sus alumnos o aprendices, mientras permanezcan bajo custodia.

La responsabilidad de que trata este artículo cesará cuando las personas de derecho privado en él mencionadas prueben que emplearon toda la diligencia de un buen padre de familia para prevenir el daño.” (Subraya la Sala)“.

Como podemos ver, la susceptibilidad de ser sancionado por una mala praxis en su gestión puede recaer inclusive por el comportamiento de sus colaboradores, por tanto es justificable plenamente la rotación de personal, despidos y contrataciones en puestos sensitivos o en aquellos donde sea necesario para en fiel cumplimiento de la tarea encomendada son aceptables, sobre considerando 
que la eficiencia de algunos colaboradores puede verse afectada por el efecto psíquico que significa trabajar sabiendo que será liquidado y por tanto su remoción o traslado son acciones típicas.

A modo de conclusión queremos subrayar que las Comisiones Liquidadoras de Cooperativas, y similares, no tienen más prohibiciones que las que le imponen las leyes especiales o su reglamento, fuera de ello su actuar se enmarca en la de un administrador por mandato y este tiene como regla principal: la diligencia de un buen padre de familia.

\section{Referencias bibliográficas}

- CABANELLAS, G. (1972). Diccionario de Derecho Usual. Tomo II. 7ma. Edición. Buenos Aires, Argentina: Editorial Heliasta.

- CAICEDO VASCO, M. (2017). Régimen Jurídico de las Cooperativas. Bogotá: Editorial Temis.

- GAITÁN SANCHEZ, Ó. M. (2014). Guía Práctica de las entidades sin ánimo de lucro y del sector solidario. Bogotá: Cámara de Comercio de Bogotá.

- GHERSI, C. A. (1999). Teoría General de la reparación de daños. Buenos Aires: Editorial Astres.

- TALEVA SALVTA, O. (2016). Cómo hacer una cooperativa. 9na. Edición. Buenos Aires. Argentina: Valletta Ediciones.

\section{LEGISLACIÓN CITADA:}

- Constitución Política de la República de Panamá.

- Código Civil de la República de Panamá.

- Código de Comercio de la República de Panamá.

- Ley 17 de 14 de mayo de 1997. Por el cual se desarrolla el artículo 283 de la Constitución Política de la República de Panamá se establece el régimen especial de las cooperativas. Gaceta Oficial 23279 de 5 de mayo de 1997.

- Decreto Ejecutivo 137 05-11-2001. Por el cual se reglamenta la Ley N ${ }^{\circ} 17$ de $1^{\circ}$ de mayo de 1997 sobre el Régimen Especial de Cooperativas. Autoridad: Ministerio de Economía y Finanzas. Gaceta Oficial 24428 de 9 de noviembre de 2001. 
- Decreto Ejecutivo 39 de 22 de octubre de 1998. Por el cual se reglamenta la Ley 17 de $1^{\circ}$ de mayo de 1997, sobre Régimen Especial de las Cooperativas. Autoridad: Ministerio de Planificación y Política Económica. Gaceta Oficial 23662 de 29 de octubre de1998.

- Resolución IPACOOP- JD. 3-91 de 28 de octubre de 1991. Reglamento de Procesos de Intervención. Autoridad: Instituto Panameño Autónomo Cooperativo. Gaceta Oficial 21918 de 20 de noviembre de 1991.

- Resolución J.D. 3 de 3 de diciembre de 2007. Mediante el cual se adopta el Reglamento de Procedimientos de las Comisiones Liquidadoras. Modificado por Resolución J.D.11-A/2010 de 30 de junio de 2010.Autoridad: Instituto Panameño Autónomo Cooperativo. Gaceta Oficial 25961 de 18 de enero de 2008. 